\title{
The search for the physical basis of memory
}

\author{
CHRIS WOLFGRAM and MELVIN L. GOLDSTEIN \\ Indiana University at Kokomo, Kokomo, Indiana
}

This paper reviews, and synthesizes on a highly theoretical level, the major ideas of Lashley, Penfield, Pribram, and others in the area of the physical basis of memory. Wolfgram's conclusions concerning this matter are that the engram is a molecular code, and that it is not a physical trace.

The field of psychology often seems to be a collection of personal opinions striving to become an organized, exact science. Nowhere is this more true than in the area of the physiological basis of memory. This paper represents an attempt to sort out various opinions and show what progress, if any, has been made in this area. ${ }^{1}$

\section{K. S. LASHLEY}

Lashley was one of the first people to attack the question of the basis of memory head-on with experimental results. Although his results would end up greatly disappointing him, his work would influence and guide his followers.

Lashley's (1960) article "In Search of the Engram" represents a major portion of his work in this area. In his experiments he used rats, monkeys, and chimpanzees, with which he took two approaches to the problem. "One," Lashley stated, "is purely behavioral and consists in the analysis of the sensory excitations which are effective in eliciting the learned reactions.... The second approach is by surgical destruction of parts of the brain" (Lashley, 1960, p. 479).

The first approach, based on the behavioral side of psychology, probably was not his favorite; Lashley did not do much experimentation in this area. Now, the surgical approach is a different story altogether. Lashley obviously loved to use his knife.

Lashley performed many experiments in the area of the engram, and most of them can be described as follows. Lashley would either (1) first destroy, disconnect, or make patterns of incisions into the area he thought had the greatest effect on learning, then train the subject to perform an associated task; or (2) train the subject beforehand, then perform one of the above types of surgery

Chris Wolfgram is currently at the University of Wisconsin, Milwaukee, in the School of Engineering. M. L. Goldstein is on the staff of Indiana University at Kokomo. He would like to express his appreciation to L. I. O'Kelly, W. R. McAllister, Kenneth R. Pahel, Ruth Hanig, Earl Wysong, and Herbert J. Goldstein for many helpful comments made during the preparation of this paper.

This work was supported in part by a small grant from the Sobel Foundation. Requests for reprints should be addressed to M. L. Goldstein, 508 Edgewater Drive, Kokomo, IN 46902. and examine any changes in the subject's ability to execute the task. The structures of the brain that were mostly involved in these experiments were the visual and motor cortices. Lashley was looking for the effects of these structures on visual discrimination and motor coordination.

The results proved to be mostly negative. Lashley found that a rat could make visual discriminations with only $1 / 16$ of its visual cortex intact. This also proved true for the motor cortex. Studies showed that when the motor cortex and the frontal poles were removed, no reduction in motor coordination was apparent. On the subject of retention, however, some different results were found.

The experiment on retention dealt with rats' learning how to get through a maze and with how destruction of a percentage of the cerebral cortex affected the number of errors made as the rats solved the puzzle. The results indicated a logarithmic relationship between the number of mistakes and the lesioned extent of the rats' brains.

Lashley's conclusions were as follows: (1) The theory of conditioned reflex paths is false. (2) Memory cannot be localized in any one area. (3) Defects caused by destruction of brain structures are not necessarily loss of memory. (4) Motor and sensory elements are not connected. (5) Within certain areas, "neurons must be sensitized to react in certain combinations"' $(1960$, p. 502$)$.

(6) There is no great excess of cells that can be reserved as the seat of special memories $(1960$, p. 502$)$.

Lashley's work was very important to this area of psychology, but his practices are not immune to criticism. Some faults-which, unfortunately, date his work-are understandable. One, in particular, is related to the period in which he worked. Freudianisms were very popular in the 1930s, the time in which Lashley worked. His experiments, which were mainly constructed on the basis of the idea of strict localization of brain functions, probably produced negative results because they were based upon that idea. These results set Lashley to his radical conclusions that were just as questionable as the localization theory.

Another situation occurring at this time that could have affected Lashley's results was a research war going on between the behaviorists and those who, like Lashley, were concentrating on physical brain function. Some have assumed that Lashley felt that this feud between those holding opposite viewpoints threatened his reputation or 
even his pride, and that this may have influenced his interpretation of his results.

For the most part, however, I think Lashley was as objective as possible; he was, after all, only human. So, even though everybody likes to see people get thrown to the lions, I think Lashley's ambition and his contributions to the field greatly outweigh the faults of his work. ${ }^{2}$

\section{WILDER PENFIELD}

Near the same time that Lashley was coming to his conclusions about the dwindling possibilities of an engram, a man by the name of Wilder Penfield was reporting different results.

Penfield, a practicing Canadian neurosurgeon, was working with patients plagued by severe epileptic seizures and was trying to find out how to go about curing them. It was common knowledge at the time that an epileptic would have certain associated hallucinations before or during an attack. Penfield reasoned that if these unwanted memories could be isolated and destroyed, the seizures connected with them would also be eliminated. This hypothesis took Penfield on a very interesting journey into the human mind.

He started, simply, with the visual cortex. Electrical stimulation provided a number of results. Some patients reported seeing brightly colored flashes of light; others reported moving forms, black patches, or even temporary blindness. Stimulation of the auditory cortex produced results such as ringing, buzzing, and hissing sounds, as well as partial deafness. Stimulation of the motor cortex produced the expected results: movements and twitching on the side of the body opposite the stimulated side of the brain. Something else happened as well. A so-called dreamy or hallucinogenic state was triggered when stimulation was applied to the temporal lobes. In a case study of a young Canadian woman referred to as M.G., Penfield $(1958$, p. 21$)$ stated that the patient had seizures associated with a hallucination of her mother singing a lullaby. During surgery on her temporal lobes, Penfield electrically stimulated specifically numbered points. The patient responded by traveling in and out of dreams concerning the sound of people entering a room, the radio, and finally, the sound of her mother's voice singing the lullaby.

Many case studies were conducted that produced results just as interesting. One of the patients was a man whose dreams consisted of vivid memories of his childhood and his old hometown. Another was a woman who described her seizures following an uncontrollable sense of déjà vu or, as she put it, "a feeling as though I lived it all before" (Penfield, 1958, p. 25-27).

As it turned out, the experiences of the patients were quite similar in type, and Penfield put them into two categories. The first he called "experiential hallucinations." These are memories from the patient's past. They can be from varying time periods and may include things still present in the patient's everyday life or things long forgotten by the conscious mind. The other category, "interpretive illusions," includes the patient's misinterpretations of current situations. These illusions can lead to feelings of déjà $v u$, unfamiliarity, changing perspective, fear, disgust, or even loneliness.

Penfield's conclusions regarding his results were as follows: (1) Strict localization of brain function does exist. (2) The stimulation stayed out of the patient's own consciousness. The patient is only aware of the movement and believes that he did not will the movement. (3) There are definite neural "organizing circuits" deep in the brain (1958, p. 6-7).

My own view of this stand is as follows: Penfield was obviously dealing with new and revolutionary findings. He conducted his experiments, for the most part, free from outside influences. This is good, generally, because it helps one keep a higher level of objectivity. However, it seems to me that Penfield totally ignored the findings of Lashley. Penfield's idea that the nervous system consists of neural circuits is totally unacceptable to anyone who has seen Lashley's findings. It seems that if these two great minds had respected each other's work, their conclusions might not seem so weak.

\section{KARL PRIBRAM}

Another man with a few original ideas about memory is Karl Pribram. The theory for which he is most famous states that the memory engram may be an interference pattern similar to that made by a laser in a hologram. This was a major departure from traditional views concerning the engram.

How did he arrive at this theory? Pribram's support for his theory came from experiments on the visual cortex of the monkey. The first of these (Pribram, 1969) had to do with visual discrimination. The monkey's visual cortex was wired to an electroencephalograph (EEG), and the monkey was conditioned to respond to a picture of a circle or a set of stripes by pressing the left or right half of a panel. The electroencephalogram was examined at the time of presentation of the stimulus, at the time of the response, and at the time of the reward (a peanut). Pribram concluded that these readings showed a distinction between various shapes that the monkey saw, but also, unexpectedly, between the side of the panel the monkey "intended" to press, and whether he was correct or incorrect in his response.

Pribram drew from this experiment the idea that visual signals distribute themselves within the visual cortex. This idea broke away from traditional views. Lashley and other psychologists of his era believed that information dealing with the visual system was very simplistically coded, but Pribram reasoned that information was modified by brain structures other than the visual cortex, in order to provide knowledge of past experience, before it would be distributed over a wide region of the brain.

A second experiment (Pribram, 1969) dealt with the modification aspect of visual input. It was based heavily 
on Hubel and Wiesel's (1959) experiments with receptive neural fields, except that Pribram used a computer to map the response of a single cell of the lateral geniculates to a moving point on a television monitor.

The first map of the receptive field was, simply, the cell's moving dot pattern as a measure of the cell's responsiveness. A second map was constructed, this time while the inferior temporal cortex was being electrically stimulated. The difference in the resulting map was that the entire receptive field was contracted when compared to the first map. The third map appeared to be expanded, in comparison with the first two, when the frontal cortex was stimulated. The primary goal of this experiment was to see where the visual system received its learned information. Pribram concluded that the inferior temporal cortex and the frontal cortex play key roles in influencing the data that reach the visual cortex.

A model resembling that of a hologram might be the key to where past experience is stored in the brain. The brain, however, would replace the coherent light in the figurative hologram with, possibly, either many parallel fibers that link the visual cortex and the retina, or the different detectors discovered in Hubel and Wiesel's (1959) experiments.

The use of the hologram as a concrete model for memory may give a probable picture of an abstract process, but Pribram arrived at this idea by the use of questionable methods.

The first, and most important, problem has to do with the interpretation of EEG tapes. The use of these tapes as concrete data can be very misleading. When Pribram finished his study using the EEG, he ended up with, at the very least, hundreds of feet of tape containing, essentially, just a lot of scribbled lines. This put Pribram in a position to exaggerate his results by finding patterns in his readings where there might not have been any. A second problem might have been Pribram's overconfidence in the ability of a monkey to "intend" to do something. This would tend to go against the principle of Occam's razor.

\section{THE CHEMICAL MEMORY}

No one prominent psychologist has been associated with the field of chemical memory storage. The idea of the engram as a chemical code has been around since the discovery of DNA as the molecular genetic code. The theory, or at least my best interpretation of it, is that when the process of learning occurs, certain chemical changes take place in the individual cells of the brain. The most common belief is that the changes occur in the cells' nuclei, specifically, in the RNA. It has not been determined whether these changes take place all over the brain (e.g., Pribram, 1969) or in a more localized manner.

Many experiments have been conducted in this area, including those of Hyden (1959), who measured increases in the RNA base ratio of a single nerve cell; Glassman (1969), who injected a radioactive precursor of RNA into rats and, as a result, found it in their RNA following training; and Bateson, Horn, and Rose (1969), who found, in the area of protein synthesis, that chicks' brain cells showed an increase in lysine after learning.

McConnell (1962) trained flatworms to turn away from light. He then fed the trained worms to a group of untrained worms, which afterward learned to avoid light more quickly than did a group fed untrained worms. McConnell concluded that the former group learned more quickly because chemicals associated with the conditioned response were already available to them. Another study worth mentioning was conducted by Ungar (1967) at Baylor College of Medicine. He trained normally nocturnal rats to avoid a darkened side of a Y-shaped box by placing electrified screens in the area. After training, Ungar made extracts from the rats' brains and found the presence of a new peptide. He then artificially duplicated it and injected it into a group of untrained rats. This group immediately chose the lighted side of the cage. Ungar's conclusion was that there might be a specific chemical assigned to every new skill learned. Other researchers (e.g., Ungar, Galvan, \& Chapouthier, 1972), using peptide synthesis, obtained similar results with goldfish. This might indicate a universal coding of peptides for memory.

My idea concerning this area is that there seems to be a connection between memory storage in neural RNA and the inability of nerve cells to reproduce. It must be mentioned that, because there are a wide range of studies and a number of people working on this subject, universal conclusions are difficult to construct. Also, many different types of lab animals have been used in these experiments, some of which (such as chicks) are not the usual test animals. The results of these experiments lack generality, in the sense that it is difficult to generalize from one laboratory to another. This point was noticed, independently, by Thompson et al. (1983).

\section{CONCLUSIONS}

As one can see, there are many open ends and unanswered questions left for the weary psychological community. We may, just now, be pointed in the right direction with research into RNA, but this is not for certain. For a major breakthrough to occur, in my opinion, someone needs to sort out, objectively, all the past studies, and generate experiments that will produce revolutionary findings. It will someday come down to that one experiment that will "bring the walls down." After that, the rest will be history.

\section{REFERENCES}

Bateson, P. P. G., Horn, G., \& Rose, S. P. R. (1969). Effects of an imprinting procedure on regional incorporation of tritiated lysine into protein of chick brain. Nature (London), 223, 534-535.

Glassman, E. (1969). The biochemistry of learning: An evaluation of the role of RNA and protein. Annual Review of Biochemistry, 38, 605-646.

Goldstein, M. L., SToller, W. L. (1982). Amygdaloid and hip- 
pocampal function in short-term retention of a classically conditioned fear response. Bulletin of the Psychonomic Society, 19, 105-107.

HuBEL, D. H., \& Wiesel, T.N. (1959). Receptive fields of single neurons in the cat's striate cortex. Journal of Physiology, 148, 574-591.

HYDEN, H. (1959). Biochemical changes in glial cells and nerve cells at varying activity. In F. Brücke (Ed.), Biochemistry of the central nervous system (Vol. 3). Oxford, England: Pergamon Press.

LASHLEY, K. S. (1960). The neuropsychology of Lashley. New York: McGraw Hill.

LaShley, K. S., Chow, K. L., \& Semmes, J. (1951). An examination of the electrical field theory of cerebral integration. Psychological Review, 58, 123-136.

MCConnell, J. V. (1962). Memory transfer through cannibalism in planarians. Journal of Neuropsychiatry, 3(Suppl. 1), 42-48.

Penfield, W. (1958). The excitable cortex in conscious man. Springfield, IL: Charles C. Thomas.

Pribram, K. H. (1969). The neurophysiology of remembering. Scientific American, 220, 73-86.

Thompson, R. F., McCormick, D. A., Lavond, D. G., Clark, G. A., KeTtNer, R. E., \& MAUK, M. D. (1983). The engram found? Initial localization of the memory trace for a basic form of associative learning. In J. M. Sprague \& A. N. Epstein (Eds.), Progress in psychobiology and physiological psychology (Vol. 10). New York: Academic Press.

UNGAR, G. (1967). Transfer of learned behavior by brain extracts. Journal of Biological Psychology, 9, 12-27.

Ungar, G., Galvan, L., \& Chapouthier, G. (1972). Evidence for chemical coding of color discrimination in goldfish brain. Experientia, 28, 1026-1027.

\section{NOTES}

1. This important paper is one result of an experiment that M. L. Goldstein ran during the fall of 1984 , on the teaching of experimental psychology to college freshmen. It is one of several "Hoosier Primitives in Experimental Psychology" that appeared at that time. It represents Chris Wolfgram's first experience with, and one of our interpretations of, a classical problem in experimental psychology. According to Wolfgram, the engram is a code, and it is not a physical trace. The code is probably in the long chain protein molecules RNA and DNA.

This approach represents a radical departure from Pribram's (1969) neural model of memory; from the experimental test of Gestalt field theory conducted by Lashley, Chow, and Semmes (1951); and from the behavioristically oriented Hullian empirical test of the memory-trace theory of memory that appeared, for the first time, in Goldstein and Stoller's (1982) experiment. It also represents a departure from Thompson et al.'s (1983) correlational approach to the same problem using electrophysical techniques.

2. The comments and criticisms expressed in the first person are the personal opinions of $\mathrm{C}$. Wolfgram and in some cases are based on information from sources (M. L. Goldstein) not cited in the text.

(Manuscript received for publication September 4, 1986.) 